\title{
Analisando as contribuiçōes do Programa Nacional pela Alfabetização na Idade Certa frente à prática pedagógica inclusiva dos professores orientadores de estudos
}

\author{
Andréia Jaqueline Devalle Rech* \\ Helenise Sangoi Antunes** \\ Cinthia Cardona de Avila*** \\ Glaucimara Pires Oliveira**** \\ Vanir Ferräo da Silva****
}

\section{Resumo}

A alfabetização dos alunos com deficiência tem sido um dos maiores desafios encontrados pelo professor durante o processo de inclusão escolar. Diante disso, investir na formação continuada desse professor irá contribuir para que ele ressignifique sua prática pedagógica levando-o a acreditar na alfabetização do aluno com deficiência. Foi problematizando essas questóes que esta pesquisa foi proposta. O objetivo do estudo foi realizar uma avaliação sobre as possíveis contribuiçóes que o Programa Nacional pela Alfabetizaçáo na Idade Certa - PNAIC trouxe aos professores orientadores de estudo, participantes do Programa, no que diz respeito à prática pedagógica frente aos alunos com necessidades educacionais especiais, por meio de uma entrevista semiestruturada. Para tanto, realizamos uma pesquisa em que participaram 347 professores orientadores de estudos do PNAIC/Rio Grande do Sul, coordenado pela Universidade Federal de Santa Maria. Após a análise desses dados, constatamos que o PNAIC contribuiu com a prática pedagógica inclusiva de $74,06 \%$ dos orientadores de estudo. Também, verificamos que o programa contribuiu significativamente para a formaçáo profissional e pessoal desses professores, proporcionando um espaço de troca de experiência culminando em reflexôes sobre suas práticas pedagógicas frente à heterogeneidade que se faz presente na sala de aula.

Palavras-chave: Educação inclusiva; Prática pedagógica; Processos de ensino e aprendizagem.

\footnotetext{
* Doutoranda em Educação pela Universidade Federal de Santa Maria, Santa Maria, Rio Grande do Sul, Brasil.

** Professora doutora da Universidade Federal de Santa Maria, Santa Maria, Rio Grande do Sul, Brasil.

*** Doutoranda em Educação pela Universidade Federal de Santa Maria, Santa Maria, Rio Grande do Sul, Brasil.

**** Professora doutora da Universidade Federal de Santa Maria, Santa Maria, Rio Grande do Sul, Brasil.

***** Pedagoga pelo Centro Universitário Franciscano - UNIFRA, Santa Maria, Rio Grande do Sul, Brasil.
} 


\section{Analyzing the contributions of the Programa Nacional pela Alfabetização na Idade Certa against inclusive classroom studies of mentor teachers}

\section{Abstract}

The literacy of students with disabilities has been one of the biggest challenges that teachers encounter during the school inclusion. Therefore, invest in continued development of this teacher will contribute to him reframe his practice leading him to believe in literacy of students with disabilities. These questions that this research was proposed was questioning. The purpose of it was to conduct a review of the possible contributions that the Programa Nacional pela Alfabetização na Idade Certa - PNAIC brought teachers guiding the study, participants in the program, with respect to pedagogical practice against pupils with special educational needs, means of a semistructured interview. Thus, we performed a survey in which 347 teachers guiding studies PNAIC/Rio Grande do Sul participated, coordinated by the Universidade Federal de Santa Maria. After analyzing the data, it was found that the PNAIC contributed the inclusive classroom of $74.06 \%$ of guiding the study. We also found that the program has contributed significantly to the professional and personal development of these teachers, providing a forum for exchange of experience culminating in reflections on their teaching practices across the heterogeneity that is present in the classroom.

Keywords: Inclusive Education; Teaching practice; Processes of teaching and learning.

\section{Apresentação}

No decorrer do ano de 2013, o Centro de Educação da Universidade Federal de Santa Maria, em conjunto com o GEPFICA - Grupo de Estudos e Pesquisas sobre Formação Inicial, Continuada e Alfabetização, em convênio com o Ministério da Educação, coordenou as atividades desenvolvidas pelo Programa Nacional de Alfabetização na Idade Certa - PNAIC. O referido Programa faz parte de um pacto federativo assumido pelo Governo Federal, Estado, Municípios e Instituiçóes de Ensino Superior com o compromisso de alfabetizar as crianças durante o Ciclo de Alfabetização. É importante ressaltar que, no Estado do Rio Grande do Sul, duas Universidades Federais ficaram responsáveis pela formação continuada dos professores que participaram do PNAIC, são elas: Universidade Federal de Santa Maria - UFSM e Universidade Federal de Pelotas - UFPel.

Os profissionais que compõem o PNAIC são distribuídos nas funções de: Coordenadores Gerais, Supervisores, Formadores, Coordenadores Locais e Orientadores de Estudos (OE). Esse grupo de professores tem a função de promover o aperfeiçoamento da formação pedagógica de professores alfabetizadores situados nas mais diversas cidades do Rio Grande do Sul (RS). 
A organização geral das atividades de formação esteve atrelada a encontros presenciais que aconteceram na cidade de Santa Maria (RS), para a formação dos OE, que posteriormente fizeram a "multiplicação" em seus municípios para os professores alfabetizadores, para as redes, Municipal e Estadual, quanto em atividades à distância, via web, para preparação dos planejamentos didáticos. O efeito desencadeado por um processo de formação continuada, interligou-se por vários profissionais da educação que fizeram a formação, a interlocução e o apoio necessários para que a formação do PNAIC pudesse ser disseminada.

As açôes do Pacto apoiaram-se em quatro eixos de atuação:

formação continuada e presencial para os professores alfabetizadores e seus orientadores de estudo; materiais didáticos, obras literárias, obras de apoio pedagógico, jogos e tecnologias educacionais; avaliaçóes sistemáticas; gestão, controle social e mobilização. (BRASIL, 2012a, p. 5).

Esses eixos articularam-se em um processo de formação de professores com base no primeiro ciclo de alfabetização. Os materiais didáticos constituíram-se por Cadernos com conteúdos que englobaram: Currículo, Currículo inclusivo, Planejamento escolar, Reflexões sobre o Sistema de Escrita Alfabética, Ludicidade, Diversidade/Heterogeneidade, Educação do Campo e Educação Especial. Tais temas são centros de debates muito sensíveis dentro das escolas, e importantes quando se almeja uma educação de boa qualidade.

Se o direito à alfabetização é uma garantia de todos os alunos, principalmente até a idade de oito anos, essa premissa deve ser para todos os que estáo na escola, independente das características e especificidades intelectuais, motoras, sensoriais e comportamentais. A finalização da escolarização sem o domínio da leitura e da escrita fluente atinge a um percentual significativo dos estudantes brasileiros, mas uma população peculiar faz parte dessas estatísticas negativas: o aluno com deficiência, que faz parte do público alvo da Educaçáo Especial.

Propor, implantar, implementar e organizar um Pacto para a alfabetização é possibilitar que todas as dificuldades e possibilidades sejam discutidas, incluindo a formação continuada do professor, as políticas de gestão e financiamento, os recursos didáticos e as práticas pedagógicas. Somando-se a isso, não se pode perder de vista qual a função da alfabetização, a dimensão que efetivamente ela atinge quando é garantida a todos, e como ela pode servir de instrumento para autonomia e humanização.

Diante disso, este trabalho tem como um de seus objetivos discutir a educação inclusiva de modo a perceber as possíveis contribuiçóes que o programa proporcionou aos professores OE envolvidos na formação do PNAIC. A educação especial é uma temática que nos sensibilizou durante os encontros de formação do PNAIC, pois sentimos as dificuldades apresentadas pela maioria das participantes em atuar frente ao aluno público-alvo da educação especial. Desse modo, na próxima seção deste texto, buscaremos situar o leitor no campo da educação especial, de acordo com 
o Caderno de Educação Especial, que se encontra entre os cadernos de formação do PNAIC.

Nesse sentido, a discussão a partir desse viés possibilitará o enfrentamento de uma realidade importante e polêmica na educação: a inclusão de alunos público-alvo da educação especial e as propostas de atuação pedagógica para a alfabetizaçáo desses alunos.

\section{Discussões sobre a educação especial nos Cadernos do PNAIC}

Atualmente, a educação especial tem atuado na perspectiva da educação inclusiva e, consequentemente, prevê a inclusão escolar dos alunos que compóem o público-alvo da educação especial. Sendo assim, de acordo com a atual Política Nacional de Educação Especial na Perspectiva da Educação Inclusiva (BRASIL, 2008), o público-alvo da educação especial engloba alunos com deficiência, transtornos globais do desenvolvimento e altas habilidades/superdotação. Nesse contexto, a educação especial é compreendida como

[...] uma modalidade de ensino que perpassa todos os níveis, etapas e modalidades, realiza o atendimento educacional especializado, disponibiliza os serviços e recursos próprios desse atendimento e orienta os alunos e seus professores quanto a sua utilizaçáo nas turmas comuns do ensino regular. (BRASIL, 2008, p. 16).

Sob a perspectiva da educação inclusiva, a educação especial está organizada de forma a perpassar tanto pelo atendimento educacional especializado quanto pela orientação ao professor comum sobre as estratégias que melhor se adéquam a cada aluno público-alvo da educação especial.

Tendo em vista que a maior parte do tempo escolar do aluno incluído é a sala de aula comum, é fundamental que o professor alfabetizador tenha acesso a uma formação continuada que o oriente para a prática da alfabetização desses alunos. Embora haja a parceria entre o educador especial, responsável pela Sala de Recursos Multifuncionais (SRMF), cabe também ao alfabetizador compreender esse aluno e criar estratégias educacionais que permitam ao aluno incluído que participe do processo de alfabetização, assim como os demais colegas.

Nesse sentido, um dos primeiros cadernos do PNAIC trouxe, para discussão, a seguinte temática: "Alfabetização de crianças com deficiência: uma proposta inclusiva" (BRASIL, 2012b). Os objetivos desse caderno foram: "compreender e desenvolver estratégias de inclusáo de crianças com deficiência visual, auditiva, motora e intelectual, no cotidiano da sala de aula"; "criar um ambiente alfabetizador, que favoreça a aprendizagem das crianças em espaços comuns" e "conhecer a importância do uso de jogos e brincadeiras no processo de apropriação do sistema alfabético de escrita, analisando jogos e planejando aulas em que os jogos sejam inclusivos, aplicados como recursos didáticos." (BRASIL, 2012b, p. 5). 
A partir da delimitação desses objetivos, alguns autores abordaram suas concepçóes acerca da alfabetização do aluno com deficiência. ${ }^{1}$ Dessa forma, elencamonos de forma relacionada aos propósitos do caderno sobre inclusão escolar.

Em relação à deficiência física, Cavalcante (2012a) optou por discutir sobre a paralisia cerebral, por ser uma das deficiências mais frequentemente observada na escola comum. Ao longo do texto, a referida autora proporciona ao professor uma leitura, de forma geral, sobre a importância da Tecnologia Assistiva (T.A) como recurso pedagógico. Recurso esse que o professor pode dispor ao aluno incluído, contribuindo, desse modo, para a autonomia/acessibilidade desse aluno. A autora cita como exemplos de T.A: “[...] um lápis engrossado, para facilitar a escrita, ou de recursos de alta tecnologia, como o uso de computadores com sistemas de comunicaçáo alternativa” (CAVALCANTE, 2012a, p. 10). Portanto, a T.A não abrange apenas recursos que requeiram um grande investimento financeiro, mas também pode contar com a criatividade do professor e a percepção do docente frente à necessidade específica que seu aluno irá apresentar.

Uma das tecnologias assitivas que a autora cita é a Comunicação Alternativa e Suplementar (CAS), um importante recurso para mediar a comunicação entre aluno com paralisia cerebral, seus colegas e professor. No entanto, esse recurso exige um trabalho de equipe, entre o professor comum e professor especialista, uma vez que é necessário "[...] realizar uma avaliação do seu aluno e da situação na qual o sistema será utilizado para determinar o que será mais útil e funcional [...]." (CAVALCANTE, 2012a, p. 11).

Outro aspecto fundamental é o professor reconhecer as potencialidades do aluno com paralisia cerebral para então explorar o que o aluno poderá evoluir. Esse fator está diretamente relacionado à alfabetização desse aluno, que requer adaptaçóes durante esse processo. Com isso, reiteramos que o professor deve ter clareza que o aluno poderá se alfabetizar com outros recursos para além do lápis e do papel, até porque são ofertados outros recursos lúdicos aos demais alunos que também beneficiarão o aluno incluído.

Cavalcante (2012a, p. 12) complementa ao citar que "as pranchas de letras são indicadas para o aluno que escolhe, letra a letra, enquanto um colega ou o professor registra a produção textual". Em relaçáo à leitura, ela poderá ser promovida com a utilizaçáo da Comunicação Suplementar e Alternativa. "As pranchas podem ser construídas com objetivos diversos e distintos, como pranchas de rotina, de contação de história, pranchas de escolhas, dentre outros conteúdos curriculares [...]" (CAVALCANTE, 2012a, p. 12).

Contudo, alfabetizar um aluno com paralisia cerebral irá exigir que o professor do ensino comum organize materiais adaptados. Para isso, o docente pode contar com apoio do professor especialista, que atua na SRMF, pois o trabalho náo se limita apenas à sala de aula comum ou à SRMF, mas sim há um trabalho integrado.

A segunda deficiência apresentada pelo Caderno de Educação Especial é a Intelectual (D.I). Aliás, por muito tempo, acreditou-se que os alunos com essa defici- 
ência não alcançariam níveis mais elevados de ensino. No entanto, com a implementação das adaptaçóes curriculares, ${ }^{2}$ esses alunos estão tendo a oportunidade de se alfabetizar e progredir na sua escolarização. O estigma da incapacidade intelectual está sendo, aos poucos, superado, sensibilizando o professor a estimular o potencial que esse aluno dispóe. Nesse sentido, quando o professor acredita na aprendizagem do aluno com D.I, ele estará dando um primeiro passo, o que é para alguns ainda difícil.

Realmente, trabalhar com um aluno com D.I é um desafio diário, de constantes retomadas de conteúdos para então dar sequência. Cavalcante (2012b, p. 16) também enfatiza que

o trabalho do professor deve priorizar o desenvolvimento intelectual e a autonomia dos seus alunos com deficiência intelectual, náo enfatizando atividades mecânicas, e sim o desenvolvimento das funçôes psicológicas superiores com aprendizagens significativas. $[\ldots]$.

Dessa forma, por meio das adaptaçôes curriculares, cabe ao professor comum, em conjunto com o professor especializado, priorizar certos conhecimentos em detrimento de outros, para que, com o andamento do ciclo de alfabetização, o aluno com D.I possa acompanhar o processo de leitura e escrita. Processo esse que terá muitos aliados, desde que bem planejados pelo professor, sendo o lúdico um dos mais importantes.

Planejar uma aula em que o lúdico irá nortear o caminho que queremos seguir é, sem dúvida, um ótimo recurso para todos os alunos, ou seja, alunos com deficiência e sem deficiência. Sob esse ponto de vista, as adaptaçôes ao aluno com D.I se reduzirão, já que, na brincadeira, todos se envolvem e têm a oportunidade de aprender brincando.

Incluir o aluno com D.I nas atividades propostas, em sala de aula, demanda dedicaçáo no planejamento, assim como para com qualquer outro aluno. Para o aluno com D.I, o professor precisará "olhar" de forma muito pontual, a fim de que perceba o potencial desse aluno. Tudo isso, pois, por muito tempo, o aluno com D.I foi copista, ou então dedicava seu tempo a pintar desenhos, atividades essas totalmente descontextualizadas das que seus colegas estavam realizando.

Portanto, para que o professor possa garantir os direitos de aprendizagem do aluno com D.I, ele precisará planejar suas aulas valorizando o seu potencial, reconhecendo o estilo de aprendizagem desse aluno e de trabalhar por meio da cooperação entre os colegas. Nesse contexto, lembramos que a alfabetização é um ciclo, o qual não se encerra ao final do terceiro ano.

Assim, precisamos ter consciência que aquele modelo de ensino, geralmente organizado em 'séries', cada uma durando um ano letivo, tem uma lógica excludente, exatamente porque trata como iguais os diferentes, dando-lhes 'a mesma dieta' e ignorando suas necessidades específicas. (MORAIS, LEITE, 2012, p. 7). 
Caso o professor não atente para esses aspectos, há grande probabilidade de o aluno com D.I não acompanhar o processo de alfabetização, "[...] restando-lhe apenas as condiçóes de inserido no universo da sala de aula, mas excluído dos processos que nela ocorrem [...]" (CAVALCANTE, 2012b, p. 17, grifo da autora).

A próxima deficiência apresentada no Caderno de Educação Especial é a cegueira e a baixa visão, material esse produzido por Seal (2012).

O aluno cego ou com baixa visão irá necessitar de adaptações que possibilitarão sua acessibilidade aos materiais disponíveis na sala de aula. Para tanto, o professor precisa conhecer as especificidades do seu aluno, tendo em vista que a baixa visão é caracterizada pela diminuiçáo do campo visual, o que requer um trabalho específico a esse aluno. Além disso, "[...] é preciso refletir que essas não poderão contar com o mesmo acesso visual aos objetos e ilustraçóes considerados atrativos utilizados com crianças videntes" (SEAL, 2012, p. 23). Nesse sentido, cabe ao professor ter percepção sobre a baixa visão do aluno e buscar alternativas que complementem o entendimento educacional desse aluno como, por exemplo, recursos ópticos e não ópticos. Os recursos ópticos

[...] constituem-se de lentes que permitem a ampliação de imagens de modo a atender as diferenças individuais de cada pessoa, portanto um mesmo auxílio óptico pode não ter a mesma eficiência para pessoas diferentes, pois cada uma apresenta um tipo de necessidade específica. (PEREIRA, COSTA, 2009, p. 93).

Dessa forma, os recursos ópticos colaboram para que o aluno com baixa visão tenha acesso aos conteúdos trabalhados em sala de aula ou entáo pelo professor especializado na SRMF. Já os recursos não ópticos auxiliam o aluno com baixa visão tornando acessíveis os materiais e o ambiente utilizados por ele. Tais recursos são: contraste, cores, iluminação, cuidado com reflexos provenientes da luz solar ou do ambiente, mesa inclinada, entre outros.

Em relação ao aluno cego, é fundamental que ele conheça o Braille, uma vez que esse código é um dos meios que esse discente utilizará para ler e escrever. Há também os softwares, como os leitores de texto, que permitem ao aluno ouvir o que escreveu ou então ter acesso a materiais digitalizados. A partir disso, é importante ressaltar que será o professor especialista o responsável por adaptar os materiais em Braille, pois a SRMF deverá ser equipada para tal tarefa, inclusive com impressoras em Braille que agiliza a leitura do aluno.

Seal (2012) aborda uma importante discussão, no caderno de educação especial, quando pontua que é fundamental o professor usar da oralidade para explicar com o máximo de detalhes, por exemplo, as ilustraçóes dos livros de literatura infantil.

Assim como as demais deficiências, a inclusão do aluno cego e com baixa visão demanda um trabalho em conjunto com o professor especializado. Essa sintonia entre esses profissionais proporcionará ao aluno incluído uma real equidade de oportunidades em sua aprendizagem. 
A discussão sobre o desafio do professor em alfabetizar um aluno surdo é apresentada por Sousa e Mourão (2012) no Caderno de Educação Especial do PNAIC. Eles também retomam o recurso da T.A como auxiliar na otimização da audição do aluno com deficiência auditiva. Esses recursos são: "[...] aparelhos de amplificação sonora, sistema de frequência modulada e implante coclear que auxiliam no processo de oralização, se estas forem devidamente acompanhadas e corretamente estimuladas para esse fim." (SOUZA, MOURÃO, 2012, p. 28).

Os mesmos autores apontam que o aluno surdo utiliza-se da visão como principal meio para sua aprendizagem e, para isso, o professor precisa estar atento à própria postura em sala de aula como, por exemplo, nunca falar de costas para os alunos, uma vez que o discente surdo poderá fazer uso da leitura labial.

No caso do aluno surdo, é preciso que tenha, na escola, um intérprete em Libras, Língua de Sinais, utilizada pelo aluno surdo para se comunicar. O intérprete, além de transmitir ao aluno surdo os conteúdos em Libras, irá também mediar as relaçôes entre professor - aluno surdo - demais alunos. Certamente, um trabalho de sensibilização com toda a escola será fundamental, ou seja, quanto mais pessoas aprenderem Libras melhor se dará a comunicação.

Como proposta educacional ao aluno surdo, tem-se utilizado a educação bilíngue, a qual valoriza a Libras como primeira língua do aluno surdo e, como segunda, a Língua Portuguesa. É fundamental que o aluno surdo tenha contato com Libras o mais cedo possível, ou seja, os pais, que na maioria são ouvintes, devem ser os primeiros a aprender Libras para se comunicar com seu filho. Além disso, a criança surda precisa ter um constante contato com outras pessoas surdas para aprimorar a Libras.

Por fim, alfabetizar um aluno surdo, em Língua Portuguesa, requer que ele assimile essa língua como sua segunda língua. Para tanto, o professor alfabetizador precisa compreender que o aluno surdo estará aprendendo uma nova língua, com uma estrutura diferente da primeira língua. Logo, cabe ao professor comum e ao intérprete organizar uma metodologia de trabalho conjunta que contribua ao aluno a apropriação da Língua Portuguesa. Sousa e Mourão (2012, p. 31) complementam ao afirmar que

Portanto, partir da língua de sinais se apresenta como uma possibilidade na alfabetização da pessoa surda, não apenas por propiciar o conhecimento de mundo, mas também por promover o desenvolvimento de habilidades metacognitivas e a construção do conhecimento [...].

A partir disso, acreditamos que a alfabetização do aluno surdo demandará um trabalho articulado, pensado para atender as especificidades desse aluno surdo, que deverá ter sua primeira língua respeitada para, então, aprender uma segunda língua.

Com a discussão em torno da surdez, encerram-se as deficiências apresentadas pelo Caderno de Educação Especial do PNAIC. Diante disso, foi possível que visualizássemos, de forma geral, os assuntos abordados em relaçáo aos alunos que 
compõem o público-alvo da educação especial e que subsidiaram as discussões dos professores $\mathrm{OE}$, nos encontros de formação, para, posteriormente, serem repassados aos alfabetizadores.

\section{Os caminhos percorridos durante a pesquisa e análise dos dados}

Os sujeitos participantes da pesquisa foram 347 professores OE, que responderam a duas questóes, durante um dos encontros de formação, que aconteceu na cidade de Santa Maria, RS. Posteriormente, as respostas dessas questóes foram transcritas pela equipe de Supervisoras Pedagógicas, autoras desse artigo, e analisadas de forma descritiva (qualitativa) e quantitativa. Para analisar de forma quantitativa, optamos por criar as seguintes categorias de análise: Contribuiu; Contribuiu parcialmente; Não contribuiu; e Não soube opinar. A partir das questốes respondidas, classificamos as respostas de acordo com as categorias acima descritas. Os OE foram identificados pelas letras do alfabeto com o intuito de preservar a identidade dos participantes da pesquisa.

Como o objetivo do trabalho discute a prática pedagógica frente aos alunos público-alvo da educação especial, optamos pela seguinte questão aos $\mathrm{OE}$ : "De que forma o pacto contribuiu para sua prática pedagógica frente aos alunos público-alvo da educação especial? Se não contribuiu, destaque os principais motivos".

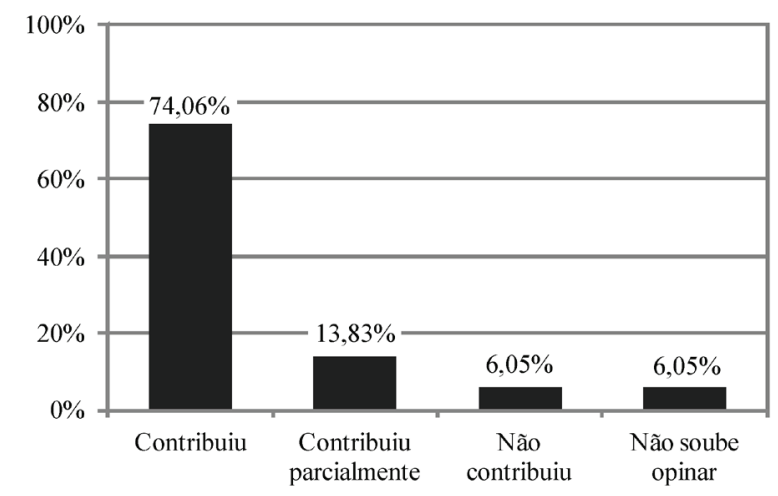

Gráfico 1: elaborado a partir das respostas das OE sobre as contribuiçóes do PACTO para sua prática pedagógica frente aos alunos público-alvo da educação especial. Fonte: Elaboração própria a partir da pesquisa realizada com os $347 \mathrm{OE}$

Após analisar as respostas, concluímos que, dentre os 347 OE, 257 responderam que o Pacto contribuiu com a prática pedagógica frente aos alunos público-alvo da educação especial. Para 48 dos professores, contribuiu parcialmente, para 21 deles não contribuiu e 21 não souberam responder.

A partir das respostas, selecionamos alguns fragmentos que ilustram os dados apresentados no gráfico acima exposto. Alguns professores relataram a importância de respeitar o ritmo de aprendizagem dos alunos com deficiência, ilustrados nos seguintes relatos: 
"Durante o estudo dos cadernos do Pacto, pude perceber que precisamos atingir a todos os educandos no que se refere a alfabetização e para isso, precisamos ter um olhar pedagógico frente as diversas necessidades educacionais existentes em nossas escolas. É preciso que sejamos criativos, persistentes e dinâmicos a fim de cativarmos os nossos educandos respeitando o tempo de cada um ao processo ensinolaprendizagem". (PROFESSORA H).
"O pacto contribuiu muito na minha prática pedagógica, pois sempre é bom compartilhar com outras pessoas que possuem habilidades e expe- riência de como trabalhar em sala de aula com essas crianças. O pacto nos mostrou outra visão da importância e valorização dessas crianças na aprendizagem, todos têm direito de aprender no seu ritmo, tempo necessário." (PROFESSORA I).
"O Pacto contribuiu muito em relação às práticas e conhecimentos rela- cionados a alunos com necessidades especiais. O pacto veio reforçar nos- so compromisso como educadores em relação a todos nossos educandos, todos têm direito em aprender, e nós precisamos compreender, identifi- car e promover atividades para todos, respeitando a evolução e o tempo de aprendizagem das crianças". (PROFESSORA T).

Essas reflexôes sobre os diferentes tempos que cada aluno apresenta em sua aprendizagem é fundamental para que o alfabetizador visualize, no aluno com deficiência, um potencial para aprender, mesmo que em um ritmo diferente dos demais colegas. Diante do exposto, Silva (2012, p. 10) afirma que:

Se temos a expectativa de que, ao término do primeiro ano do Ciclo de Alfabetização, a maioria das crianças já tenha construído uma hipótese alfabética de escrita, compreendemos também que, muitas vezes, algumas crianças precisarão de um tempo maior para compreender como funciona a escrita alfabética. No entanto, o respeito à diversidade de percursos de aprendizagem dos alunos não significa a ausência de metas em relação à alfabetização, pois todas as crianças têm o direito de aprender a ler e escrever com autonomia até o final do terceiro ano do Ensino Fundamental.

Sob este ponto de vista, é necessário respeitar os diferentes ritmos de aprendizagem dos alunos, incluindo os com deficiência, mas isso não significa que o professor crie baixas expectativas em relaçáo à aprendizagem desse aluno. Ao contrário, cabe ao professor planejar atividades que contemplem os diferentes conhecimentos dos seus alunos, de forma a contribuir para a evolução de sua aprendizagem. Logo, a partir do planejamento, o professor "[...] cria oportunidades diferenciadas para cada criança, o que pode representar um ganho significativo na direção da formação de todos, sem excluir ninguém, e na garantia da construção dos direitos de aprendizagem por todas as crianças em tempo oportuno" (CRUZ, MANZONI, SILVA, 2012, p. 8). 
Dessa forma, o planejamento também esteve presente nos relatos dos professores, como se comprova a seguir:

\begin{abstract}
"Muito contribuiu, pois os professores repensaram suas práticas de sala de aula buscando alcançar aquelas crianças que não estavam sendo aceitas onde os professores é que estavam resistentes em ter esse aluno. Hoje os professores contemplam em seu planejamento atividades para esse aluno, buscam mais informaçōes". (PROFESSORA L).

"Contribuiu, pois mudou-se o foco, a forma de pensar dos professores, sendo que ao invés de pensar na aprovaçāo ou reprovação se está pensando em como auxiliar esse aluno para que o mesmo tenha êxito, repensando e planejando atividades pertinentes para cada caso". (PROFESSORA M).
\end{abstract}

Esses dois relatos trazem à tona a reflexão do professor sobre sua prática em sala de aula. Dizem respeito ao planejamento que o alfabetizador deve organizar para respeitar a singularidade no tempo de aprender de cada aluno com deficiência. Aborda sobre a resistência de alguns professores em receber em suas turmas os alunos de inclusão. Fato esse que remete à formação inicial desses professores, sendo que, muitos deles, não tiveram, em sua grade curricular, disciplinas que abordassem sobre a educaçáo especial e/ou educação inclusiva.

Sendo assim, consideramos que o Pacto contribuiu com discussóes acerca do processo de inclusáo dos alunos com deficiência, conforme apresentado anteriormente no Caderno de Educação Especial.

A aprovação/retenção é sempre um assunto muito polêmico, que gera muitas discussóes entre os educadores. Mas, conforme relatou a professora "M", os professores estão mudando o foco, pensando para além da aprovação/retenção, estão sim se preocupando com a aprendizagem do aluno com deficiência. Dessa forma, "mesmo quando chegam ao final do ano sem dominar os conhecimentos que o professor buscou ensinar, as crianças têm agregado saberes; é preciso identificar não apenas o que elas não aprenderam, mas também o que elas aprenderam, e valorizar suas conquistas" (LEAL, CRUZ, ALBUQUERQUE, 2012, p. 11).

Logo, o planejamento de atividades direcionadas para os alunos público-alvo da educação especial é um dos passos para uma efetiva inclusão escolar. Nesse aspecto, as adaptações curriculares são um excelente recurso que o professor dispóe para planejar sua aula pensando nos potenciais e nas dificuldades apresentadas pelo aluno com deficiência.

\footnotetext{
"As açóes do Pacto contribuíram no sentido de possibilitar o direcionamento de um novo olhar para esses alunos e igualmente para o grupo, com o intuito de desconstruir práticas excludentes, tornando as práticas transformadoras que considerem o aluno como sujeito ativo no processo de aprendizagem e respeitem suas capacidades, potencialidades e principalmente o direito de estar na escola e conviver com os outros colegas." (PROFESSORA N).
} 
"Contribui reafirmando que todos somos diferentes e respeitar essas
diferenças e indispensável. Acredito que outro aspecto importante é o
olhar frente a cada um e o planejamento de atividades diferenciadas
para atender as necessidades das crianças respeitado etapas do desenvol-
vimento e potencialidades. Mas em contrapartida temos dificuldade
de realizar um trabalho de rede. Os educadores ainda necessitam de
auxilio, de apoio, de formaçâa, de ajuda especializada." (PROFES-
SORA O).

A partir dos relatos das professoras, verificamos a preocupação com a inclusão escolar dos alunos com deficiência. Para Rodrigues (2006, p. 311),

\begin{abstract}
a proposta pedagógica da Educaçáo Inclusiva passa claramente pela oferta de oportunidades de aprendizagem diversificadas aos alunos. Se a 'diferença é comum a todos' e assumimos a classe como heterogênea, é importante responder a essa heterogeneidade em termos de estratégia de ensino e aprendizagem.
\end{abstract}

Estratégias essas adotadas pela professora "P", como se pode observar abaixo:

"Tenho dois alunos incluidos e as formaçōes do pacto muito contribuiu para o meu trabalho de ensino aprendizagem dos mesmos. Passei a contemplá-los de forma diferenciada, respeitando suas limitaçóes, criando estratégias e novas formas de melhor contemplá-los com a aprendizagem, tenho hoje muita segurança para trabalhar com eles passou a ansiedade e aquele medo de náo conseguir ensinar nada".

Logo, para que a inclusão seja efetivada é preciso, sim, criar estratégias que promovam a aprendizagem do aluno com deficiência, valorizando o que ele alcançou ao longo do ciclo de alfabetização. Com essas ações, será possível conceber a inclusão para além da garantia de matrícula, mas também para a permanência, com um ensino de qualidade, para esse aluno na escola comum, conforme relato da professora "A":

\begin{abstract}
"Penso que o PACTO trouxe clareza com relação a inclusão, porque muitos professores ainda tinham a ideia de que colocar uma classe a mais na sala seria uma forma de inclusão, acho que a teoria nos auxiliou na prática diferenciando o que é inserir e o que é incluir".
\end{abstract}

Dessa forma, o pacto veio a contribuir para que o professor repensasse sua atuação perante os alunos com deficiência, tendo em vista que a inclusão escolar é uma realidade, e o professor poderá receber a qualquer momento um aluno com deficiência em sua sala de aula. Segue o relato da professora "Q" que mostra essa preocupação:

\footnotetext{
"Contribuiu nos mostrando alternativas para que o trabalho com crianças com necessidades especiais seja realizado com êxito. Mostrando também que precisamos estudar sempre e estar preparados para receber os mesmos em nossas salas a qualquer momento".
}

Já o relato da Professora "R" demonstra a preocupação com os materiais adaptados, já que eles são fundamentais para a inclusão escolar. Na visão dessa professora: 
"O PACTO contribuiu para a minha prática pedagógica através dos materiais de leitura que me fizeram refletir sobre os alunos com deficiência numa perspectiva de aprendizagem e não da limitação. Porém observei que no material disponibilizado aos alunos (jogos e livros de literatura) não recebemos especifico para os alunos com deficiência, como por exemplo, material em braille. Nâo temos alunos com cegueira na escola, mas poderemos vir a tê-los. Entendo que o professor deve confeccionar e adaptar os materiais para trabalhar com os alunos com deficiência, mas penso que deveriam ter pensado nestes alunos ao enviar materiais para as escolas".

Nesse sentido, para a professora "R", o Pacto contribuiu ao proporcionar uma reflexão sobre a prática frente aos alunos com deficiência. No entanto, reconhece que há muito, ainda, o que ser discutido e refletido para que a inclusão escolar aconteça de fato e não apenas de direito.

\section{Considerações finais}

Após análise dos dados, constatamos que o PNAIC contribuiu com a prática pedagógica de 74,06\% dos professores $\mathrm{OE}$, o que equivale a $257 \mathrm{OE}$, de um total de 347 participantes da pesquisa. Esses dados revelam uma porcentagem significativa da contribuição do PNAIC, um Programa de Formaçáo Continuada, no que diz respeito à prática pedagógica dos professores frente aos alunos com deficiência.

Em relação aos 13,83\%, ou seja, 48 dos professores $\mathrm{OE}$ manifestaram que o PNAIC contribuiu parcialmente com sua prática pedagógica inclusiva. Segundo relatos dos próprios entrevistados, o programa poderia ter sido mais aprofundado nas discussóes em torno da alfabetização desses alunos. Logo, foi possível verificarmos que, embora o PNAIC não tenha seu foco central na alfabetização dos alunos com deficiência, essa é uma realidade presente no cotidiano escolar, o que demanda um maior tempo de discussão e aprofundamento dessa temática.

Desse modo, acreditamos que, apesar do PNAIC ter elaborado um Caderno específico sobre a Educação Especial, não foi suficiente para suprir as demandas que os professores estấo enfrentando cotidianamente em suas salas de aulas.

É importante ressaltar que o grupo de professores formadores de Santa Maria engajou-se para que o tema da alfabetização dos alunos com deficiência fosse abordado com maior frequência durante os encontros de formação. Isso foi um aspecto muito positivo, pois vários relatos dos $\mathrm{OE}$ exemplificaram a importância das trocas de experiências oportunizadas durante os encontros de formação, o que contribuiu para qualificar suas práticas pedagógicas. Além disso, a coordenaçáo geral do PNAIC de Santa Maria convidou palestrantes qualificados na área da educação inclusiva para proferir palestras sobre esse tema durante os encontros de formação, os quais ocorreram ao longo de 2013.

Por fim, a docência com alunos que apresentam deficiências requer conhecimento e entendimento do processo de ensino e aprendizagem específicos, com os recursos didáticos adequados que possam auxiliar na aquisição da leitura e da escrita, 
nos vários serviços pedagógicos que contemplam a alfabetização, substitutivos ou não. Aliás, a prática de uma educação inclusiva, isto é, para todos, apesar de polêmica enquanto política pública, precisa fazer parte de forma incisiva dos contextos de formação continuada, principalmente daqueles que priorizam a prática pedagógica dos professores, como na característica do PNAIC, assim como das discussóes realizadas na escola, trazendo o professor como ator e autor da inclusão. O conhecimento científico e teórico deve aperfeiçoar e refletir a própria prática, articulando-a com os conhecimentos vivenciados na escola.

Diante disso, a fim de aperfeiçoar o Pacto da matemática, que iniciou em março de 2014, sugerimos que o tema inclusão escolar seja mais aprofundado. Isso por que, conforme preocupaçóes relatadas, verificamos o quanto os professores precisam estar preparados para enfrentar a heterogeneidade em sala de aula.

\section{Referências}

BRASIL, Secretaria de Educação Básica. Diretoria de Apoio à Gestão Educacional. Pacto Nacional pela Alfabetizaçáo na Idade Certa: formaçáo de professor alfabetizador: Caderno de apresentação. Ministério da Educação, Secretaria de Educação Básica, Diretoria de Apoio à Gestão Educacional. Brasília: MEC, SEB, 2012a.

. Caderno de educaçáo especial: a alfabetização de crianças com deficiência: uma proposta inclusiva. Ministério da Educação, Secretaria de Educação Básica, Diretoria de Apoio à Gestão Educacional. Brasília: MEC, SEB, 2012b.

BRASIL, Ministério da Educação. Secretaria de Educação Especial. Política Nacional de Educaçáo Especial na Perspectiva da Educaçáa Inclusiva. Brasília, 2008. Disponível em: <http://portal.mec.gov.br/arquivos/pdf/ politicaeducespecial.pdf>. Acesso em: 29 mar. 2014.

Projeto Escola Viva - Garantindo o acesso e permanência de todos os alunos na escola - Alunos com necessidades educacionais especiais. Brasília, 2000.

CAVALCANTE, T. C. F. A pessoa com deficiência motora frente ao processo de alfabetização. In: BRASIL, Secretaria de Educação Básica. Diretoria de Apoio à Gestão Educacional. Caderno de educaçáo especial: a alfabetização de crianças com deficiência: uma proposta inclusiva. Ministério da Educação, Secretaria de Educação Básica, Diretoria de Apoio à Gestáo Educacional. Brasília: MEC, SEB, 2012a.

Pensando a alfabetização da pessoa com deficiência intelectual. In: BRASIL, Secretaria de Educação Básica. Diretoria de Apoio à Gestão Educacional. Caderno de educaçáo especial: a alfabetização de crianças com deficiência: uma proposta inclusiva. Ministério da Educação, Secretaria de Educação Básica, Diretoria de Apoio à Gestão Educacional. Brasília: MEC, SEB, 2012b.

CRUZ, M. do C. S.; MANZONI, R. M.; SILVA, A. M. P. da. Planejamento no ciclo de alfabetizaçấo: objetivos e estratégias para o ensino relativo ao componente curricular - Língua Portuguesa. In: BRASIL, Secretaria de Educação Básica. Diretoria de Apoio à Gestão Educacional. Pacto nacional pela alfabetizaçáo na idade certa: a organização do planejamento e da rotina no ciclo de alfabetização na perspectiva do letramento: Ano 2: unidade 2. Ministério da Educação, Secretaria de Educação Básica, Diretoria de Apoio à Gestão Educacional. Brasília: MEC, SEB, 2012.

LEAL, T. F.; CRUZ, M. do C. S.; ALBUQUERQUE, E. B. C. de. Heterogeneidade e direitos de aprendizagem na alfabetização: os diferentes percursos dos estudantes. In: BRASIL, Secretaria de Educação Básica. Diretoria de Apoio à Gestão Educacional. Pacto nacional pela alfabetizaçáo na idade certa: a alfabetização para todos: diferentes percursos, direitos iguais. Ano 1, Unidade 7. Ministério da Educaçáa, Secretaria de Educaçấo Básica, Diretoria de Apoio à Gestão Educacional. Brasília: MEC, SEB, 2012.

MORAIS, A. G. de; LEITE, T. M. S. B. R. Direitos de aprendizagem, heterogeneidade dos aprendizes e atendimento à diversidade, no final do ciclo de alfabetizaçáo: diagnosticando e organizando as crianças na sala de aula. Ministério da Educação, Secretaria de Educação Básica, Diretoria de Apoio à Gestão Educacional. Brasília: MEC, SEB, 2012. 
PEREIRA, J. L. C. e COSTA, M. da P. R. da - O aluno com deficiência visual em sala de aula: informaçốes gerais para professores de artes. Revista Eletrônica de Educaçáa. São Carlos, SP: UFSCar, v. 3, n. 1, p. 89-99, mai. 2009. Disponível em: <http://www.reveduc.ufscar.br>. Acesso em: 27 maio 2014.

RODRIGUES. D. Dez idéias (mal)formadas sobre a educação inclusiva. In: RODRIGUES, D. (Org.). Inclusáo e Educaçáo: doze olhares sobre a educação inclusiva. São Paulo: SUMUS, 2006.

SEAL, A. G. de S. Estratégias de ensino na alfabetização da pessoa cega e com baixa visão. In: BRASIL, Secretaria de Educação Básica. Diretoria de Apoio à Gestão Educacional. Caderno de educaçáo especial: a alfabetizaçáo de crianças com deficiência: uma proposta inclusiva. Ministério da Educação, Secretaria de Educação Básica, Diretoria de Apoio à Gestão Educacional. Brasília: MEC, SEB, 2012.

SILVA, A. A heterogeneidade no processo de alfabetizaçáo: diferentes conhecimentos, diferentes atendimentos. In: BRASIL, Secretaria de Educação Básica. Diretoria de Apoio à Gestâo Educacional. Pacto nacional pela alfabetizaçáo na idade certa: a heterogeneidade em sala de aula e os direitos de aprendizagem no ciclo de alfabetização. Ministério da Educação, Secretaria de Educação Básica, Diretoria de Apoio à Gestão Educacional. Brasília: MEC, SEB, 2012.

SOUSA, W. P. de A.; MOURÃO, Carlos Antonio Fontenele. A alfabetização da pessoa surda: desafios e possibilidades. In: BRASIL, Secretaria de Educação Básica. Diretoria de Apoio à Gestão Educacional. Caderno de educaçáo especial: a alfabetização de crianças com deficiência: uma proposta inclusiva. Ministério da Educação, Secretaria de Educaçáo Básica, Diretoria de Apoio à Gestão Educacional. Brasília: MEC, SEB, 2012.

\section{Notas}

${ }^{1} \mathrm{O}$ caderno de Educaçăo Especial não engloba a alfabetização das crianças com altas habilidades/superdotaçáo e transtornos globais do desenvolvimento. Por isso, ao longo do texto, utilizaremos apenas o termo deficiência.

${ }^{2}$ Adaptaçốes curriculares são "[...] respostas educativas que devem ser dadas pelo sistema educacional, de forma a favorecer a todos os alunos e, dentre estes, os que apresentam necessidades educacionais especiais" (BRASIL, 2000, p. 8, grifos das autoras).

\section{Correspondência}

Andréia Jaqueline Devalle Rech - Universidade Federal de Santa Maria, Centro de Educação. Avenida Roraima, Camobi. CEP: 97105-900 - Santa Maria, Rio Grande do Sul, Brasil.

E-mail: prof.andirech@gmail.com - professora@helenise.com.br - cinthysm@yahoo.com.br - glauci_27@hotmail.com - vanirfs@uol.com.br

Recebido em 10 de outubro de 2014

Aprovado em 15 de dezembro de 2014 
